\section{LAS GARANTÍAS EXPLÍCITAS DE SALUD: UN GRAN NEGOCIO PARA LAS ISAPRES}

Por Ramiro de Elejalde, académico FEN UAH.

La ley 19.966 (2004) introdujo el programa de Garantias Explicitas de Salud (más conocido como GES o AUGE) cuyo objetivo es garantizar el acceso, oportunidad, calidad y protección finande enfermedades como diasetes hipertensión arterial, depresión, cáncer de mama, etc. Para una persona que sufre alguna de estas enfermedades, el programa GES le asegura un copago establecido por ley para las prestaciones asociadas a dicha enfermedad un tope al gasto de bolsillo por año.

La creciente utilización del programa demuestra que los inficiario it valoran positivamente. Pero tambièn tiene un beneSuperintendera. las propias Isapres. Segun un informe de la gastaron solamente un 37 por ciento de los recursos GES en

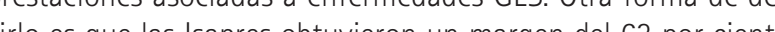
de su "negocio GES".

¿Cómo hicieron las Isapres para hacer tan buen negocio?

Para entenderlo, debemos conocer el financiamiento del programa GES. El Ministerio de Hacienda determina, cada tres años, los recursos disponibles para el financiamiento del GES en Fonasa. En base a estos recursos se calcula el valor de la Prima Universal, que establece un techo para el costo esperado individua del programa por año en Fonasa. Luego el Ministerio de Salud, en función de la Prima Universal, define las enfermedades y procedimientos cubiertos por el GES.

Por su parte, las Isapres están obligadas a asegurar las enfermedades GES a partir del sexto mes de la publicación del decreto GES. Para tinanciar el gasto en GLS, las Isapres tienen 90 dias para informar la prima Ges que cobraran a sus afiliados. Esta prima La figura 1 nos muestra la evolución de la Prima Universaly prima GES (promedio entre las Isapres más grandes) desce 2005 prasta 2018 .

La Prima Universal ha ido aumentando a medida que se incorporaron más enfermedades GES. 25 enfermedades en 2005, 40 en 2006, 57 en el periodo 2007-2009, 69 en 2010-2012, y 80 en 2013-2018.

La prima GES también ha ido aumentando en el tiempo pero a una velocidad mayor que la Prima Universal: la Prima Universal se triplica entre 2005 y 2016 mientras que la prima GES aumenta às de siete veces.

Además es llamativo que la prima GES se encuentre un 38 por ciento por debajo de la Prima Universal hasta 2012, pero supere a la Prima Universal en un 39 por ciento en 2016-2018.

Es ilustrativo fijar la mirada en el cambio de primas entre el periodo 2012-2015 y 2016-2018. Para el periodo 2016-2018 el Ministerio de Hacienda aumentó la Prima Universal un 2,7 por ciento. de 3,77 UF a 3,87 UF. En consecuencia, el Ministerio de Salud mantuvo las 80 enfermedades GES del periodo 2012-2015, pero introdujo cambios menores en las condiciones de cobertura: se agregaron medicamentos para EPOC, el asma adulto y la artritis idiopatica juvenil, además se incorporaron nuevas prestaciones $y$

las primas GES para cada ntaron entre un 30 por ciento y por ciento.

¿Porqué las Isapres aumentan las primas?

Los principales argumentos son que sus afiliados utilizan disintos prestadores que los afiliados de Fonasa y estos prestadores tienen precios superiores; las distintas caracteristicas de los clienes de Isapres y Fonasa; el mayor uso efectivo del sistema GES en . Aunque algunos de estos argumentos pueden ser validos, ninguno justifica un aumento pronunciado de las primas en el tiempo. De hecho, los informes presentados por las mismas isapres deben De Existe las lsapres para justificar la mayor prima.

Existe una explicasin jas sinple: es un mecanismo encubierto Pecios es los planes de salud? La respuesta es no.

los precio base y una del plan que paga un individuo surge de multiplicar el precio base por el factor que corresponda al individuo. Entonces el precio del plan de salud puede aumentar por dos vias:

Cambios en el precio base del plan: Las Isapres pueden cambiar los precios base de los planes de salud una vez al año.

2) Cambios en el factor del individuo a medida que aumenta su edad.

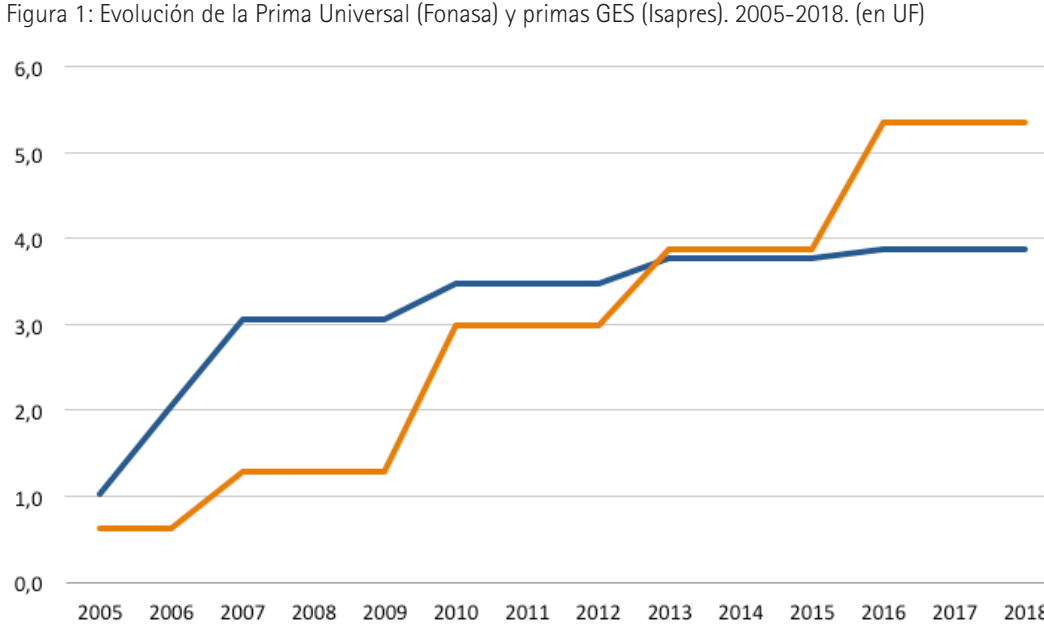

El problema para las Isapres es que a parîr de 2005, el gobierno les limitó la libertad jar bandas de variación de los precios.

Además, desde 2007 se presentan recursos de protección ante cambios de los precios de los planes complementarios y la Corte Suprema de Justicia automaticón proteción presentados por a decursos de precios de los planes de salud Desce 2010 fueron aumentando constantemente desde 8 mil recursos presentados en 2010 143 mil recursos presentados en 2016. Con una cartera de 2 millones de cotizantes, los recursos de protección limitan la facultad de aumentar los precios por parte de las Isapres (además de tener afrontar los costos de los juicios).

Por uitimo, en un fallo de agosto de 2010, el Tribunal Constitucional no perm tió que se siga aplicando la tabla de factores hasta que los legisladores establezcan cias de factores por sexo yor las diferenDias de factores por sex y edad.

Ge abrit de 2017 la Corte Supipres, ló en su contra ante los 42 mil recursos de protección presentados por el alza de las primas GES. La corte determinó que Prima Universal era un tope máximo para las primas GES que puede fijar las Isapres. El mercado de los seguros de salud pirvado en Chile se encuentra en un limbo regulatorio a causa de los fallos judiciales la falta de voluntad politica de realizar una reforma en el sistema. En este limbo, las Isapres utilzan un politica bien intencionada como el GES para saltarse restricciones regulatorias y judiciales para aumenlos un pres be de los planes. Posiblemente sean los abogados que presentan los recursos de protección y obtienen grandes beneficios. En este sentido, una reform del sistema de Isapres debería ser una de as prioridades del gobierno entrante.

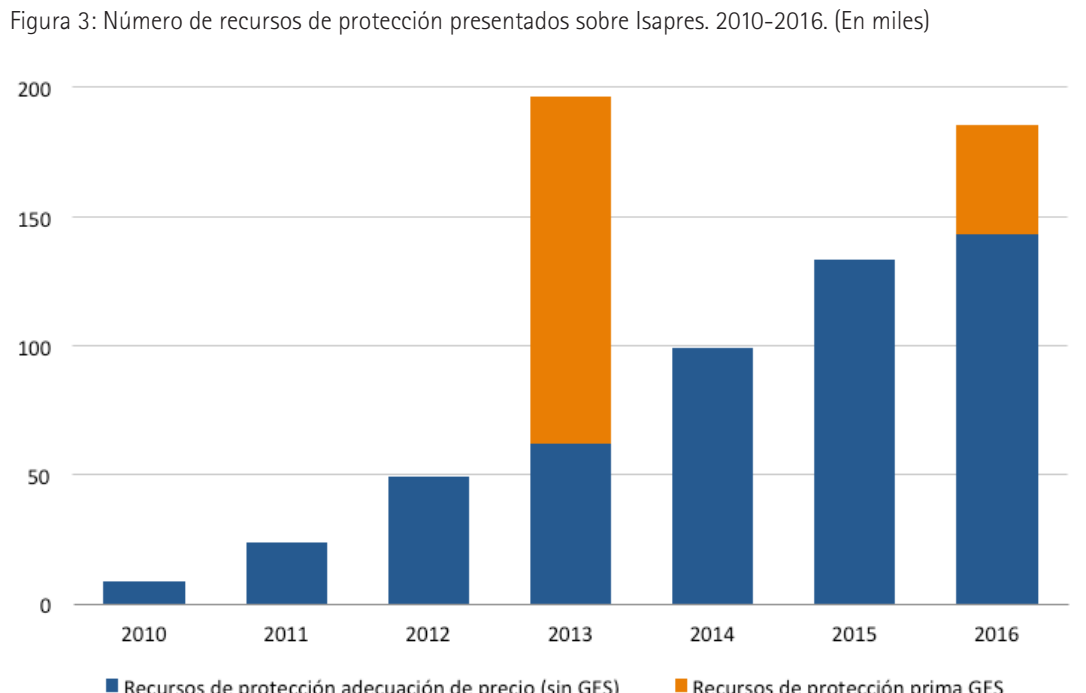
Fono Facultad: 28897366 